\title{
Factors predicting the outcomes of elderly hospitalized myasthenia gravis patients: a national database study
}

This article was published in the following Dove Press journal:

International Journal of General Medicine

20 April 2017

Number of times this article has been viewed

\author{
Somsak Tiamkao ${ }^{1,2}$ \\ Sineenard Pranboon ${ }^{3}$ \\ Kaewjai Thepsuthammarat ${ }^{4}$ \\ Kittisak Sawanyawisuth ${ }^{1,5,6}$ \\ 'Department of Medicine, Faculty \\ of Medicine, ${ }^{2}$ The Neuroscience \\ Research and Development Group, \\ ${ }^{3}$ Nursing Division, Srinagarind \\ Hospital, ${ }^{4}$ Clinical Epidemiology Unit, \\ Faculty of Medicine, ${ }^{5}$ Research Center \\ in Back, Neck, Other Joint Pain and \\ Human Performance (BNOJPH), \\ ${ }^{6}$ Ambulatory Medicine Research \\ Group, Khon Kaen University, Khon \\ Kaen, Thailand
}

Background: Myasthenia gravis (MG) in elderly populations is increasing. This study aimed to evaluate predictors for treatment outcomes in elderly hospitalized MG patients using the national database.

Methods: We collected data of elderly hospitalized MG patients from the National Health Security Office from October 2009 to September 2010. Predictors for treatment outcomes were examined.

Results: During the study period, 1,948 identified MG patients were admitted to hospitals throughout Thailand. Of those, 441 patients $(22.64 \%$ ) were aged $\geq 60$ years. There were 66 patients (14.97\%) who had poor outcomes. There were only three significant factors in the final model. Presence of pneumonia, use of mechanical ventilators, and septicemia had adjusted odds ratios ( $95 \%$ confidence interval) of 2.83 (1.03, 7.75), 5.33 (2.24, 12.72), and 4.47 (1.86, 10.75), respectively. Conclusion: Pneumonia, being on a mechanical ventilator, and septicemia were independent factors associated with poor treatment outcomes in elderly hospitalized MG patients according to national data.

Keywords: pneumonia, ventilator, mortality, predictor

\section{Introduction}

Myasthenia gravis (MG) is an autoimmune disorder affecting neuromuscular transmission leading to fluctuating muscle weakness that is most common in young women. ${ }^{1,2}$ Data on MG prevalence and incidence vary widely among countries. It has a prevalence rate of 15-179 per million and an incidence rate of 3-30 per million. ${ }^{3,4}$ Inpatient prevalence was 8.0 per 100,000 population. ${ }^{5}$ The prevalence rate of MG increased from 8.4 per 100,000 in 2000 to 14.0 per 100,000 in 2007 , while the incidence rate was 2.1 per 100,000 population. $^{6}$

In the last three decades, MG incidence has increased in the elderly ${ }^{2,5,7,8}$ and may also be underdiagnosed ${ }^{2,9,10}$ due to atypical MG presentation in those patients. Patients with dysarthria or difficulties swallowing may be hospitalized for cerebrovascular disease workups and doctors may be unaware of any neuromuscular disorder. ${ }^{2}$ Due to the increasing prevalence of MG in elderly patients, this study aimed to investigate risk factors for MG treatment outcomes by using the national database.

\section{Methods Study design}

This is a retrospective study that explored national data on $M G$ patients aged $\geq 60$ years and hospitalized in the year 2010. Data were retrieved from the national health

Correspondence: Somsak Tiamkao Medicine, Khon Kaen University, 123 Mitraphrap Road, Khon Kaen, 40002, Thailand

Tel +6643363664

Fax +66 43348399

Email somtia@kku.ac.th 
insurance system. The system consisted of three kinds of health insurance: universal coverage, social welfare, and government welfare. Universal coverage is basic health insurance for the general population, while social welfare and government welfare are provided to people who work for private companies and government organizations, respectively. The International Classification of Diseases, Tenth Edition (ICD-10) code (G70) was used to identify eligible patients. Medical discharge forms were used to retrieve data about each patient's clinical characteristics, complications, treatments, discharge status, hospital fees, and length of hospital stay.

There are three hospital categories in Thailand including primary or community, secondary, and tertiary hospitals. The primary or community hospitals serve at the district or community levels and usually have 10-30 beds. The secondary hospitals provide health care at the provincial level, while the tertiary hospitals, such as university hospitals and large provincial hospitals, are referral centers.

Discharge statuses of all admitted patients were defined by attending physicians according to four levels: complete recovery, improved, not improved, and death. The first two categories were classified as improved or good outcomes, while the latter two were considered not improved or poor outcomes. Each eligible patient was put into one of the two groups based on these outcomes.

\section{Statistical analysis}

Data were categorized by treatment outcomes; good and poor. Clinical features and treatment outcomes for each were compared using descriptive statistics. Factors associated with poor outcome were analyzed by multivariate logistic regression analysis. All analyses were performed with the SPSS software (IBM Corp., Armonk, NY, USA).

\section{Ethical consideration}

The study protocol was approved by the ethics committee in human research, Khon Kaen University (HE591353). Written informed consent from each patient was waived by the ethics committee because it used only retrospective, de-identified patient data.

\section{Results}

During the study period, 1,948 identified MG patients were admitted to hospitals throughout Thailand. Of those, 441 patients $(22.64 \%)$ were aged $\geq 60$ years. There were 66 patients $(14.97 \%)$ who had poor outcomes at discharge. The mean age of patients with poor outcomes was slightly higher than those with good outcomes (71.4 vs 69.6 years; $p$-value $0.065)$. The percentage of males was also slightly higher in the poor outcome group than in the good outcome group (47.0\% vs $39.5 \%$; $p$-value 0.254 ), as shown in Table 1 . The mortality rate was $9.3 \%$ or 41 patients and categorized by age group as follows: $<70$ years, 17 patients; 70-80 years, 18 patients; and $>80$ years, 6 patients ( $p$-value for difference in age group 0.066).

Using univariate analysis, it was determined that there were five significant factors associated with poor outcomes, including the presence of pneumonia, respiratory failure, septicemia, use of mechanical ventilators, and hospital bills (Table 1). Septicemia had the highest unadjusted odds ratio at 10.02. The average length of stay in the poor outcome group was longer than that in the good outcome group (15.6 vs 10.6 days; $p$-value 0.054$)$, while the average hospital bill was significantly higher in the poor outcome group $(112 \mathrm{k}$ vs 58k Baht; $p$-value 0.032).

After adjustment, there were only three significant factors remaining in the model. Presence of pneumonia, use of mechanical ventilators, and septicemia had adjusted odds ratios (95\% confidence interval) of $2.83(1.03,7.75)$, $5.33(2.24,12.72)$, and $4.47(1.86,10.75)$, respectively (Table 2).

\section{Discussion}

MG is more common in young adults than in the elderly and is more prominent in females as opposed to males. The national data in our study showed that the male:female ratio in the elderly was close to one (40.6:59.4), as shown in Table 1. These findings were similar to those in other studies. ${ }^{8,11-14}$ Two studies from India and Sri Lanka found that overall male:female ratios were 2.7:1.0 and 2.0:1.2, respectively. ${ }^{15,16}$ The study from India also found that patients with ages $\geq 60$ years were commonly male. Both studies had small sample sizes and focused on specific study populations, those associated with thymoma or undergoing immunosuppressive therapy. Generally, MG is still a disease most common in young women and elderly men. ${ }^{8,11-14}$

The prognosis of hospitalized MG patients in our study was good; $85 \%$ of patients were discharged with improved status. The mortality rate in the elderly subjects was higher than in the US (9.3\% vs 2.2\%). ${ }^{13}$ A study from Denmark and systematic review showed the highest mortality rate of 1.81 per million (range 1.5-2.2).$^{3,14}$ The specific mortality rate of $\mathrm{MG}$ crisis was $4.47 \% .{ }^{13}$ In this study, however, the mortality rate referred to overall mortality, not mortality specific to MG crisis. There were 20 patients $(4.5 \%)$ 
Table I Factors affecting treatment outcomes in elderly hospitalized myasthenia gravis patients by univariate logistic regression analysis

\begin{tabular}{|c|c|c|c|c|c|c|}
\hline \multirow[t]{3}{*}{ Factors } & & \multicolumn{2}{|c|}{ Outcomes $(n=44 I)$} & \multirow[t]{3}{*}{ Crude OR } & \multirow[t]{3}{*}{$95 \% \mathrm{Cl}$} & \multirow[t]{3}{*}{$p$-value } \\
\hline & & Good & Poor & & & \\
\hline & & $n=375(\%)$ & $n=66(\%)$ & & & \\
\hline Age, years & Mean (SD) & $69.6(7.2)$ & $71.4(7.3)$ & 1.03 & $(1.00,1.07)$ & 0.065 \\
\hline \multirow[t]{2}{*}{ Gender } & Male & $148(39.5)$ & $31(47.0)$ & I & - & \\
\hline & Female & $227(60.5)$ & $35(53.0)$ & 1.36 & $(0.80,2.30)$ & 0.254 \\
\hline \multirow[t]{3}{*}{ Insurance type } & GWME & $129(34.4)$ & $28(42.4)$ & I & - & \\
\hline & SSF & $16(4.3)$ & $0(0.0)$ & & & \\
\hline & UC & $230(6 \mid .3)$ & $38(57.6)$ & 0.76 & $(0.45,1.30)$ & 0.316 \\
\hline \multirow[t]{4}{*}{ Hospital level } & Primary & $20(5.3)$ & $\mathrm{I}(\mathrm{I} .5)$ & 1 & - & 0.266 \\
\hline & Secondary & $64(17.1)$ & $16(24.2)$ & 5.00 & $(0.62,40.09)$ & \\
\hline & Tertiary & $75(20.0)$ & $14(2 \mid .2)$ & 3.73 & $(0.46,30.12)$ & \\
\hline & Private & $216(57.6)$ & $35(53.0)$ & 3.24 & $(0.42,24.92)$ & \\
\hline \multirow[t]{4}{*}{ Region } & Northern & $73(19.5)$ & $16(24.2)$ & I & - & 0.489 \\
\hline & Northeast & $81(21.6)$ & $10(15.2)$ & 0.56 & $(0.24,1.32)$ & \\
\hline & Central & $202(53.9)$ & $35(53.0)$ & 0.79 & $(0.4 I, I .5 I)$ & \\
\hline & Southern & $19(5.1)$ & $5(7.6)$ & 1.20 & $(0.39,3.69)$ & \\
\hline \multirow[t]{2}{*}{ Pneumonia $^{a}$} & No & $353(94.1)$ & $46(69.7)$ & 1 & - & \\
\hline & Yes & $22(5.9)$ & $20(30.3)$ & 6.98 & $(3.54,13.76)$ & $<0.001$ \\
\hline \multirow[t]{2}{*}{ Respiratory failure } & No & $342(9 \mid .2)$ & $40(60.6)$ & I & - & \\
\hline & Yes & $33(8.8)$ & $26(39.4)$ & 6.74 & $(3.66,12.39)$ & $<0.001$ \\
\hline \multirow[t]{2}{*}{ Septicemia ${ }^{a}$} & No & $356(94.9)$ & $43(65.2)$ & 1 & - & \\
\hline & Yes & $19(5.1)$ & $23(34.9)$ & 10.02 & $(5.05,19.88)$ & $<0.001$ \\
\hline \multirow[t]{2}{*}{ Intravenous immunoglobulin } & No & $356(94.9)$ & $65(98.5)$ & 1 & - & \\
\hline & Yes & $19(5.1)$ & $\mathrm{I}(1.5)$ & 0.29 & $(0.04,2.19)$ & 0.229 \\
\hline \multirow[t]{2}{*}{ Plasmapheresis } & No & $371(98.9)$ & $64(97.0)$ & 1 & - & \\
\hline & Yes & $4(I .1)$ & $2(3.0)$ & 2.90 & $(0.52,16.15)$ & 0.225 \\
\hline \multirow{2}{*}{ On continuous invasive MV } & No & $329(87.7)$ & $32(48.5)$ & I & - & \\
\hline & Yes & $46(12.3)$ & $34(51.5)$ & 7.60 & $(4.29,13.48)$ & $<0.001$ \\
\hline \multirow{2}{*}{ Thymectomy } & No & $362(96.5)$ & $66(100.0)$ & & & \\
\hline & Yes & $13(3.5)$ & $0(0.0)$ & & & \\
\hline Length of stay, days & Mean (SD) & $10.6(17.7)$ & $15.6(22.2)$ & 1.01 & $(1.00,1.02)$ & 0.054 \\
\hline Hospital charge $(\times 10,000)$ & Mean (SD) & $5.8(15.5)$ & $11.2(17.3)$ & 1.02 & $(1.00,1.03)$ & 0.032 \\
\hline
\end{tabular}

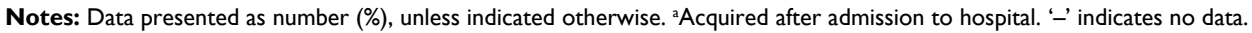

Abbreviations: OR, odds ratio; Cl, confidence interval; GWME, Government Welfare Medical Expense; SSF, Social Security Fund; UC, universal coverage; MV, mechanical ventilator; $\mathrm{SD}$, standard deviation.

Table 2 Significant factors affecting poor treatment outcomes in elderly hospitalized myasthenia gravis patients by multivariate logistic regression analysis

\begin{tabular}{llll}
\hline Factors & $\begin{array}{l}\text { Adjusted } \\
\text { odds ratio }\end{array}$ & $\begin{array}{l}\text { 95\% confidence } \\
\text { interval }\end{array}$ & p-value \\
\hline Pneumonia & 2.83 & $1.03,7.75$ & 0.043 \\
On continuous invasive MV & 5.33 & $2.24,12.72$ & $<0.001$ \\
Septicemia & 4.47 & $1.86,10.75$ & 0.001 \\
\hline
\end{tabular}

Abbreviation: MV, mechanical ventilator.

who received intravenous immunoglobulin (IVIG) and 6 patients (1.4\%) who received plasmapheresis, which were indicators for MG crisis. Elderly patients may have better prognoses with pyridostigmine, steroids, azathioprine, a combination of immunosuppressive drugs, IVIG, or plasmapheresis. ${ }^{17,18}$
Treatment with surgical thymectomy is a good alternative. Patients receiving thymectomy are usually younger than patients not undergoing the operation ${ }^{14-19}$ and have a higher remission rate. ${ }^{19-21}$ The remission rate of $\mathrm{MG}$ after thymectomy was $30 \%-40 \%$. There were only 13 patients $(3.5 \%)$ receiving thymectomies in this study due to the elderly study population. In this study, we were not able to analyze whether or not thymectomies were associated with discharge outcomes (Table 2). This finding may be explained by the fact that all patients who received a thymectomy were admitted to hospital for this operation.

Factors independently associated with discharge status were mostly due to complications during admission. Presence of pneumonia, being on a mechanical ventilator, and septicemia were factors associated with morbidity 
and mortality. ${ }^{22,23}$ Among these three factors, being on a mechanical ventilator was the factor with the highest adjusted odds ratio (Table 2 ). These factors may result in longer hospital stays and higher costs. Elderly patients tend to have more complications, especially sepsis, than young adults. ${ }^{20}$

This study used the national database. Therefore, it may represent a bird's eye view of MG. However, some limitations exist. First, data were retrieved only from discharge summaries. We were not able to identify disease severity or data for individual patients such as the age of presumed incident of MG or steroid treatment. The IVIG and plasmapheresis were seldom used in this study population due to insurance issue. Most patients in this study had basic health insurance or universal cover which meant limitation in treatment. Additionally, these results may apply only to hospitalized MG patients, not including those MG patients who were treated at the outpatient department. Data on initial MG class at admission were not evaluated, but most hospitalized MG patients in Thailand were class III or IV. Lastly, the number of patients treated with IVIG and plasmapheresis were limited due to availability of that treatment and lack of experienced physicians.

\section{Conclusion}

Pneumonia, being on a mechanical ventilator, and septicemia were important factors associated with poor treatment outcomes in hospitalized elderly MG patients according to national data.

\section{Acknowledgments}

The authors thank Mr Dylan Southard for his kind English editing of the manuscript via Research Affair, Faculty of Medicine, Khon Kaen University, Thailand; the Thailand Research Fund (TRF): IRG 5780016, and the Higher Education Research Promotion National Research University Project of Thailand, Office of the Higher Education Commission through the Health Cluster (SHeP-GMS), Thailand; the Faculty of Medicine, Khon Kaen University grant number TR57201; the TRF Senior Research Scholar Grant, Thailand Research Fund grant number RTA5880001; and grant of Faculty of Medicine, Khon Kaen University, Thailand (Grant Number RG59301).

\section{Disclosure}

The authors report no conflicts of interest in this work.

\section{References}

1. Binks S, Vincent A, Palace J. Myasthenia gravis: a clinical-immunological update. J Neurol. 2016;263(4):826-834.

2. Aarli JA. Myasthenia gravis in the elderly: is it different? Ann NY Acad Sci. 2008;1132:238-243.

3. Carr AS, Cardwell CR, McCarron PO, McConville J. A systematic review of population based epidemiological studies in Myasthenia Gravis. BMC Neurol. 2010;10:46.

4. McGrogan A, Sneddon S, de Vries CS. The incidence of myasthenia gravis: a systematic literature review. Neuroepidemiology. 2010; 34(3):171-183.

5. Cetin H, Fülöp G, Zach H, Auff E, Zimprich F. Epidemiology of myasthenia gravis in Austria: rising prevalence in an ageing society. Wien Klin Wochenschr. 2012;124(21-22):763-768.

6. Lai CH, Tseng HF. Nationwide population-based epidemiological study of myasthenia gravis in Taiwan. Neuroepidemiology. 2010;35(1):66-71.

7. Casetta I, Groppo E, De Gennaro R, Cesnik E, Piccolo L, Volpato S, Granieri E. Myasthenia gravis: a changing pattern of incidence. J Neurol. 2010;257(12):2015-2019.

8. Gattellari M, Goumas C, Worthington JM. A national epidemiological study of Myasthenia Gravis in Australia. Eur J Neurol. 2012; 19(11):1413-1420.

9. Vincent A, Clover L, Buckley C, Grimley Evans J, Rothwell PM; UK Myasthenia Gravis Survey. Evidence of underdiagnosis of myasthenia gravis in older people. J Neurol Neurosurg Psychiatry. 2003;74(8): $1105-1108$.

10. Kleiner-Fisman G, Kott HS. Myasthenia gravis mimicking stroke in elderly patients. Mayo Clin Proc. 1998;73(11):1077-1078.

11. Aragones JM, Altimiras J, Roura P, et al. Prevalence of myasthenia gravis in the Catalan country of Osona. Neurologia. 2017;32(1):1-5.

12. Blum S, Lee D, Gillis D, McEniery DF, Reddel S, McCombe P. Clinical features and impact of myasthenia gravis disease in Australian patients. J Clin Neurosci. 2015;22(7):1164-1169.

13. Alshekhlee A, Miles JD, Katirji B, Preston DC, Kaminski HJ. Incidence and mortality rates of myasthenia gravis and myasthenic crisis in US hospitals. Neurology. 2009;72(18):1548-1554.

14. Christensen PB, Jensen TS, Tsiropoulos L, et al. Mortality and survival in myasthenia gravis: a Danish population based study. J Neurol Neurosurg Psychiatry. 1998;64(1):78-83.

15. Singhal BS, Bhatia NS, Umesh T, Menon S. Myasthenia gravis: a study from India. Neurol India. 2008;56(3):352-355.

16. Gunaratne PS, Larsen HA, Manatunga AK. Effectiveness of immunotherapy in myasthenia gravis: epidemiological evidence from Sri Lanka. Neurology Asia. 2005;10:39-45.

17. Hellmann MA, Mosberg-Galili R, Steiner I. Myasthenia gravis in the elderly. J Neurol Sci. 2013;325(1-2):1-5.

18. Evoli A, Batocchi AP, Minisci C, Di Schino C, Tonali P. Clinical characteristics and prognosis of myasthenia gravis in older people. J Am Geriatr Soc. 2000;48(11):1442-1448.

19. Kawaguchi N, Kuwabara S, Nemoto Y, et al. Treatment and outcome of myasthenia gravis: retrospective multi-center analysis of 470 Japanese patients, 1999-2000. J Neurol Sci. 2004;224(1-2):43-47.

20. Donaldson DH, Ansher M, Horan S, Rutherford RB, Ringel SP. The relationship of age to outcome in myasthenia gravis. Neurology. 1990;40(5):786-790.

21. Remes-Troche JM, Téllez-Zenteno JF, Estañol B, Garduño-Espinoza J, García-Ramos G. Thymectomy in myasthenia gravis: response, complication, and associated conditions. Arch Med Res. 2002;33(6):545-551.

22. Tiamkao S, Pranboon S, Thepsuthammarat K, Sawanyawisuth K. Prevalence of factors associated with poor outcomes of hospitalized myasthenia gravis patients in Thailand. Neurosciences (Riyadh). 2014;19(4):286-290.

23. Sieb JP. Myasthenia gravis: an update for the clinician. Clin Exp Immunol. 2014;175(3):408-418. 
The International Journal of General Medicine is an international, peer-reviewed open-access journal that focuses on general and internal medicine, pathogenesis, epidemiology, diagnosis, monitoring and treatment protocols. The journal is characterized by the rapid reporting of reviews, original research and clinical studies across all disease areas.
The manuscript management system is completely online and includes a very quick and fair peer-review system, which is all easy to use. Visit http://www.dovepress.com/testimonials.php to read real quotes from published authors.

Submit your manuscript here: https://www.dovepress.com/international-journal-of-general-medicine-journal 